\title{
Characterization of Phytophthora capsici Isolates from Processing Pumpkin in Illinois
}

\author{
S. Z. Islam, M. Babadoost, K. N. Lambert, and A. Ndeme, Department of Crop Sciences, University of Illinois, \\ Urbana 61801; and H. M. Fouly, Department of Natural Resources and Environmental Sciences, University of Illi- \\ nois, Urbana 61801
}

\begin{abstract}
Islam, S. Z., Babadoost, M., Lambert, K. N., Ndeme, A., and Fouly, H. M. 2004. Characterization of Phytophthora capsici isolates from processing pumpkin in Illinois. Plant Dis. 89:191197.

This study was conducted to investigate pathogenic, morphologic, and genetic variations among Phytophthora capsici isolates from processing pumpkin (Cucurbita moschata) fields in Illinois. Random amplified polymorphic DNA (RAPD) markers were employed to assess genetic variation among 24 isolates of $P$. capsici from 10 individual fields at six locations. Unweighted mean pair group analysis clustered isolates into six groups. The genetic distances ranged from 0.03 to 0.45 . Inoculation of pumpkin seedlings in the greenhouse revealed that the isolates belonged to six distinct genetic groups differing significantly $(P=0.05)$ in virulence. Isolates tested exhibited four growth patterns in culture: cottony, rosaceous, petaloid, and stellate. P. capsici isolates, including an ATCC isolate (ATCC-15427), with cottony growth pattern did not grow at $36^{\circ} \mathrm{C}$. The mean oospore diameter of A1 mating type isolates was greater than that of $\mathrm{A} 2$ mating type isolates. Nine of 24 isolates tested produced chlamydospores in $\mathrm{V} 8-\mathrm{CaCO}_{3}$ liquid medium.
\end{abstract}

Additional keywords: cucurbit, Phytophthora blight

Illinois ranks first in pumpkin production in the United States, producing about $90 \%$ of the country's commercial processing pumpkins (4). Phytophthora blight, caused by Phytophthora capsici Leonian, has become one of the most serious threats to processing pumpkin (Cucurbita moschata L.) production in Illinois and has caused up to $100 \%$ yield losses (3). P. capsici can attack the host plant at any growth stage and causes seedling death, crown rot, foliar blight, and fruit rot. The pathogen also causes severe crop losses in other cucurbits, eggplant, pepper, and tomato $(8,11,13,19)$.

P. capsici is a soilborne oomycete. It can survive in soil as oospores for several years, and repeated cultivation of susceptible hosts results in a high density of oospores in soil (8). Free water either in soil or on the foliage favors asexual reproduction of the pathogen with the formation of sporangia and zoospores $(5,6)$. Propagules of $P$. capsici are dispersed by water, soil, and air currents (20). Infection of the foliage of pumpkin occurs when zoospores of $P$. capsici are splashed onto the plant surfaces from the soil during rainfall or irrigation (13).

Corresponding author: M. Babadoost
E-mail: babadoos@uiuc.edu

Accepted for publication 26 September 2004.

DOI: 10.1094/PD-89-0191

(C) 2005 The American Phytopathological Society
Variation in virulence among isolates of $P$. capsici has been reported. Lee et al. (13) studied aggressiveness of $P$. capsici isolates from pepper and pumpkin on pumpkin cultivars and found differences in virulence among the isolates. Ristaino (19) evaluated the relative virulence of isolates of $P$. capsici from cucumber and squash on pepper, and reported variation among the isolates. There is no published report available on pathogenic variation among isolates of $P$. capsici from processing pumpkin.

During the past 5 years, we observed that the severity of Phytophthora blight and yield losses differed among processing pumpkin fields. In some fields, seedling death was so widespread that the growers had to replant fields two or three times. In a survey of affected commercial fields, with the same processing pumpkin cultivars and grown under similar conditions, incidence of vine blight ranged from 4 to $48 \%$, leaf blight from 17 to $68 \%$, and fruit rot from 4 to $71 \%$. Also, we observed variation in growth and sporulation among $P$. capsici isolates from processing pumpkin fields. For example, some isolates grew above $36^{\circ} \mathrm{C}$, while most of the isolates did not; some isolates produced chlamydospores; and oospores formed in cultures of single mating type. These observations raised the question whether the isolates of $P$. capsici in different processing pumpkin fields vary in virulence.

The objective of this study was to investigate pathogenic, morphologic, and ge- netic variation among isolates of $P$. capsici from processing pumpkin fields in Illinois. Mating types, chlamydospore formation, and temperature/growth response of the isolates were also investigated.

\section{MATERIALS AND METHODS}

Isolates. Fifty-seven single-zoospore isolates of $P$. capsici, collected from 22 processing pumpkin fields in six towns in central Illinois during 2000 and 2001 (Table 1), were used in this study. P. capsici was isolated from infected plant tissues dipped in $70 \%$ ethanol for $3 \mathrm{~min}$, rinsed in sterilized distilled water (SDW), and plated on PARPH (Corn meal agar, 17 $\mathrm{g}$; pimaricin, $10 \mathrm{mg}$; ampicillin, $250 \mathrm{mg}$; rifampicin, $10 \mathrm{mg}$; PCNB, $100 \mathrm{mg}$; hymexazol, $50 \mathrm{mg}$; and distilled water, 1,000 $\mathrm{ml}$ ), a selective culture medium for $P$ capsici. Cultures were maintained on lima bean agar (LBA; Difco Laboratories, Detroit, MI; $23 \mathrm{~g} /$ liter) slants at room temperature (5). The isolates were identified as $P$. capsici based on colony morphology and sporangial characteristics.

Sporangia were measured by placing a drop of water on a slide, touching it to the colony surface of 5- to 6-day-old cultures grown on V8 juice medium under white fluorescent light at $24^{\circ} \mathrm{C}$, covering with a coverslip, and examining using light microscopy (19). Twenty arbitrarily chosen sporangia were examined and measured for each isolate using an optical micrometer.

PCR-based identification of isolates. For DNA extraction, isolates were grown separately in $100 \mathrm{ml}$ of lima bean broth in 250-ml Erlenmeyer flasks for 5 days at $24^{\circ} \mathrm{C}$. Mycelia were harvested by filtration and ground to a fine powder in liquid nitrogen using a mortar and pestle. Genomic DNA was extracted from frozen mycelium using the procedure developed by Nelson et al. (17) and dissolved in Tris-EDTA buffer. The identification of collected isolates as $P$. capsici was confirmed by polymerase chain reaction (PCR) using the $P$. capsici specific primer PCAP and the internal transcribed spacer (ITS) primer ITS1 according to the method developed by Ristaino et al. (21). The PCAP primer in combination with ITS1 primer amplifies an approximately 172-bp product of ribosomal DNA of $P$. capsici (21). PCR amplification products were separated by electrophoresis in $2 \%$ agarose gels stained with 
ethidium bromide, and product size was determined by comparison with a molecular size marker.

Colony characteristics. Plugs $(7 \mathrm{~mm}$ diameter) of mycelium in agar from the edge of a 4-day-old culture of $P$. capsici were placed onto the center of petri plates containing Difco potato dextrose agar (PDA), and the plates were incubated in darkness at $24^{\circ} \mathrm{C}$. After 5 days, the plates were visually examined for colony texture and appearance. For temperature/growth responses, a mycelial disk $(7 \mathrm{~mm}$ diameter) was placed in the center of each LBA plate. Inoculated plates were incubated at temperatures of $10,15,20,24,30,32,35$, 36,37 , and $38^{\circ} \mathrm{C}\left( \pm 0.2^{\circ} \mathrm{C}\right)$ in a completely randomized design. Each isolate had three replicates. Colony diameter was measured after 3, 5, and 7 days of incubation, and data were converted to radial growth in

Table 1. Mating types, diameter of oospore, and colony characteristics of isolates of Phytophthora capsici from processing pumpkin fields in Illinois

\begin{tabular}{|c|c|c|c|c|c|c|c|c|}
\hline \multirow[b]{2}{*}{ Isolate $^{w}$} & \multirow[b]{2}{*}{ Field no. $(\text { town })^{x}$} & \multirow[b]{2}{*}{ Plant part } & \multirow{2}{*}{$\begin{array}{c}\text { Year } \\
\text { isolated }\end{array}$} & \multirow[b]{2}{*}{ Mating type } & \multirow{2}{*}{$\begin{array}{l}\text { Oospore } \\
\text { diam. }(\mu \mathrm{m})^{\mathrm{y}}\end{array}$} & \multirow{2}{*}{$\begin{array}{l}\text { Growth } \\
\text { pattern }\end{array}$} & \multicolumn{2}{|c|}{ Colony growth $(\mathrm{mm} / \mathrm{day})$} \\
\hline & & & & & & & $35^{\circ} \mathrm{C}$ & $36^{\circ} \mathrm{C}$ \\
\hline Pc1 & 1 (Pekin) & Seedling & 2000 & A1 & $34.16 b^{z}$ & Cottony & 8.5 & 0.0 \\
\hline Pc2-1 & 2 (Pekin) & Seedling & 2000 & A1 & $33.12 \mathrm{~b}$ & Cottony & 7.2 & 0.0 \\
\hline Pc2-5 & 2 (Pekin) & Leaf & 2000 & A2 & $27.72 \mathrm{c}$ & Cottony & 4.7 & 0.0 \\
\hline Pc4 & 3 (Pekin) & Vine & 2000 & A2 & $26.12 \mathrm{c}$ & Stellate & 5.1 & 1.8 \\
\hline Pc9 & 4 (Pekin) & Fruit & 2000 & A1 & $37.16 \mathrm{a}$ & Stellate & 7.6 & 2.5 \\
\hline Pc10 & 5 (Pekin) & Petiole & 2000 & A2 & $25.00 \mathrm{~cd}$ & Petaloid & 10.1 & 1.8 \\
\hline Pc11 & 6 (Green Valley) & Petiole & 2000 & A2 & $23.54 \mathrm{~d}$ & Rosaceous & 4.3 & 1.7 \\
\hline Pc12 & 7 (Green Valley) & Petiole & 2000 & A2 & - & Stellate & 8.8 & 2.0 \\
\hline Pc13 & 8 (Pekin) & Petiole & 2000 & A1 & $38.40 \mathrm{a}$ & Stellate & 7.8 & 1.9 \\
\hline $\operatorname{Pc} 15$ & 9 (Manito) & Petiole & 2000 & A2 & $23.83 \mathrm{~d}$ & Stellate & 6.2 & 2.5 \\
\hline Pc16 & 10 (Manito) & Petiole & 2000 & A2 & $27.55 \mathrm{c}$ & Stellate & 8.3 & 2.7 \\
\hline Pc18 & 11 (Manito) & Petiole & 2000 & A2 & $26.00 \mathrm{c}$ & Stellate & 8.1 & 2.8 \\
\hline Pc20 & 12 (Pekin) & Seedling & 2000 & A1 & $32.28 \mathrm{~b}$ & Stellate & 6.9 & 2.2 \\
\hline $\operatorname{Pc} 21$ & 13 (Pekin) & Seedling & 2000 & A2 & $26.79 \mathrm{c}$ & Stellate & 7.5 & 2.1 \\
\hline $\mathrm{Pc} 22$ & 14 (Pekin) & Seedling & 2000 & A2 & $26.87 \mathrm{c}$ & Stellate & 8.0 & 2.3 \\
\hline Pc24-1 & 15 (Manito) & Fruit & 2001 & A1 & $35.00 \mathrm{~b}$ & Stellate & 9.4 & 3.8 \\
\hline Pc24-2 & 15 (Manito) & Fruit & 2001 & A1 & $33.13 \mathrm{~b}$ & Stellate & 6.6 & 2.3 \\
\hline Pc24-3 & 15 (Manito) & Fruit & 2001 & A1 & - & Stellate & 4.5 & 2.2 \\
\hline Pc24-4 & 15 (Manito) & Fruit & 2001 & A1 & - & Stellate & 4.8 & 2.2 \\
\hline Pc24-5 & 15 (Manito) & Fruit & 2001 & A1 & $33.75 \mathrm{~b}$ & Stellate & 4.3 & 2.4 \\
\hline Pc24-6 & 15 (Manito) & Fruit & 2001 & A1 & $32.29 \mathrm{~b}$ & Stellate & 4.3 & 2.1 \\
\hline Pc31 & 16 (Green Valley) & Soil & 2001 & A1 & - & Stellate & 6.0 & 2.3 \\
\hline Pc33-1 & 17 (Green Valley) & Petiole & 2001 & A1 & - & Petaloid & 7.0 & 3.0 \\
\hline Pc33-3 & 17 (Green Valley) & Petiole & 2001 & A1 & $33.12 \mathrm{~b}$ & Petaloid & 7.2 & 2.2 \\
\hline Pc33-4 & 17 (Green Valley) & Petiole & 2001 & A1 & $33.54 \mathrm{~b}$ & Petaloid & 7.4 & 2.0 \\
\hline Pc33-5 & 17 (Green Valley) & Petiole & 2001 & A1 & $31.46 \mathrm{~b}$ & Petaloid & 7.6 & 1.6 \\
\hline Pc33-6 & 17 (Green Valley) & Petiole & 2001 & A1 & $34.00 \mathrm{~b}$ & Petaloid & 5.8 & 3.0 \\
\hline Pc33-7 & 17 (Green Valley) & Petiole & 2001 & A1 & - & Petaloid & 6.2 & 3.1 \\
\hline Pc33-8 & 17 (Green Valley) & Petiole & 2001 & A1 & $33.64 \mathrm{~b}$ & Petaloid & 7.9 & 2.4 \\
\hline Pc33-9 & 17 (Green Valley) & Petiole & 2001 & A1 & $33.43 \mathrm{~b}$ & Petaloid & 5.3 & 3.2 \\
\hline Pc34-1 & 18 (Machinaw) & Petiole & 2001 & A2 & $27.00 \mathrm{c}$ & Rosaceous & 6.8 & 3.4 \\
\hline Pc34-3 & 18 (Machinaw) & Petiole & 2001 & A2 & $26.34 \mathrm{c}$ & Rosaceous & 7.2 & 3.3 \\
\hline Pc34-4 & 18 (Machinaw) & Vine & 2001 & A2 & $25.41 \mathrm{c}$ & Rosaceous & 6.7 & 2.6 \\
\hline Pc34-5 & 18 (Machinaw) & Petiole & 2001 & A2 & $24.00 \mathrm{~cd}$ & Rosaceous & 6.2 & 2.6 \\
\hline Pc34-7 & 18 (Machinaw) & Petiole & 2001 & A2 & $26.79 \mathrm{c}$ & Rosaceous & 6.0 & 2.2 \\
\hline Pc34-8 & 18 (Machinaw) & Vine & 2001 & A2 & $25.78 \mathrm{c}$ & Rosaceous & 6.0 & 2.3 \\
\hline Pc34-11 & 18 (Machinaw) & Petiole & 2001 & A2 & $26.87 \mathrm{c}$ & Rosaceous & 5.3 & 2.3 \\
\hline Pc35-4 & 19 (Allentown) & Petiole & 2001 & A2 & $27.60 \mathrm{c}$ & Stellate & 4.8 & 2.2 \\
\hline Pc35-6 & 19 (Allentown) & Petiole & 2001 & A2 & $27.00 \mathrm{c}$ & Stellate & 6.0 & 2.4 \\
\hline Pc35-7 & 19 (Allentown) & Leaf & 2001 & A2 & $24.79 \mathrm{~cd}$ & Stellate & 6.3 & 2.1 \\
\hline Pc35-9 & 19 (Allentown) & Petiole & 2001 & A2 & $23.75 \mathrm{~d}$ & Stellate & 6.5 & 2.4 \\
\hline Pc35-10 & 19 (Allentown) & Petiole & 2001 & A2 & $26.77 \mathrm{c}$ & Stellate & 6.2 & 2.8 \\
\hline Pc36-1 & 20 (Forest city) & Petiole & 2001 & A2 & $22.60 \mathrm{~d}$ & Stellate & 8.9 & 4.0 \\
\hline Pc36-2 & 20 (Forest city) & Petiole & 2001 & A2 & $22.17 \mathrm{~d}$ & Stellate & 10.1 & 6.2 \\
\hline Pc36-3 & 20 (Forest city) & Fruit & 2001 & A1 & $32.92 \mathrm{~b}$ & Stellate & 8.5 & 4.0 \\
\hline Pc36-4 & 20 (Forest city) & Petiole & 2001 & A2 & $22.92 \mathrm{~d}$ & Stellate & 8.7 & 4.0 \\
\hline Pc36-5 & 20 (Forest city) & Fruit & 2001 & A1 & $38.56 \mathrm{a}$ & Stellate & 7.8 & 3.8 \\
\hline Pc36-7 & 20 (Forest city) & Petiole & 2001 & A1 & $33.02 \mathrm{~b}$ & Stellate & 8.2 & 3.9 \\
\hline Pc36-8 & 20 (Forest city) & Petiole & 2001 & A1 & $32.63 \mathrm{~b}$ & Stellate & 9.6 & 4.0 \\
\hline Pc36-9 & 20 (Forest city) & Petiole & 2001 & A1 & $35.13 \mathrm{~b}$ & Stellate & 5.3 & 3.8 \\
\hline Pc38-8 & 21 (Manito) & Leaf & 2001 & A1 & - & Petaloid & 6.8 & 2.5 \\
\hline Pc38-11 & 21 (Manito) & Leaf & 2001 & A1 & $32.46 \mathrm{~b}$ & Petaloid & 6.1 & 2.5 \\
\hline Pc38-12 & 21 (Manito) & Petiole & 2001 & A1 & $33.00 \mathrm{~b}$ & Petaloid & 4.1 & 2.7 \\
\hline Pc38-13 & 21 (Manito) & Petiole & 2001 & A1 & $32.92 \mathrm{~b}$ & Petaloid & 5.6 & 2.2 \\
\hline Pc38-14 & 21 (Manito) & Vine & 2001 & A1 & $35.00 \mathrm{~b}$ & Petaloid & 4.6 & 2.2 \\
\hline Pc38-15 & 21 (Manito) & Vine & 2001 & A1 & - & Petaloid & 5.1 & 2.8 \\
\hline Pc39-2 & 22 (Manito) & Petiole & 2001 & A2 & - & Petaloid & 4.0 & 3.2 \\
\hline ATCC 15427 & - & - & - & A1 & - & Cottony & 3.1 & 0.0 \\
\hline ATCC15399 & - & - & - & A2 & - & Stellate & 4.0 & 1.7 \\
\hline
\end{tabular}

${ }^{w}$ Isolates marked in bold were used for chlamydospore formation, virulence test, and random amplified polymorphic DNA (RAPD) analysis. ATCC isolates obtained from American Type Culture Collection Center.

${ }^{x}$ All six towns (locations) are in central Illinois.

y Mean of 50 oospores.

z Values in the column with a letter in common are not significantly different according to Fisher's protected LSD test $(P=0.05)$. 
millimeters per day. The experiment was repeated twice.

Mating type. All isolates were tested to determine mating type by pairing with known A1 (ATCC-15427) or A2 (ATCC15399) tester isolates of $P$. capsici that were obtained from the American Type Culture Collection (ATCC). Plugs of mycelium in agar (7 $\mathrm{mm}$ diameter) from advancing margins of 4-day-old cultures were placed $2 \mathrm{~cm}$ apart on clarified V8 juice agar and incubated at $24^{\circ} \mathrm{C}$ in darkness for 3 weeks (19). The absence of oospores at the interface between colonies indicated the same mating type, whereas the presence of oospores indicated opposite mating type. The solo culture of each isolate was examined for oospore formation as a control. The positive control was a cross between two tester isolates of opposite mating types. Twenty-four isolates from each A1 or A2 mating type were arbitrarily selected for oospore measurement. For each isolate, 25 oospores closest to the A1 isolate (initial inoculum disk) and closest to the A2 isolate were measured for diameter using an optical micrometer and compared. The experiment was repeated once. The data were analyzed using the analysis of variance procedure of SAS (SAS Institute, Cary, NC).

Chlamydospore formation. Twentyfour isolates of P. capsici (Table 1), four from each town (location), were selected arbitrarily and cultured on modified cleared $\mathrm{V} 8-\mathrm{CaCO}_{3}$ liquid medium (V8 juice, $100 \mathrm{ml}$; filtered $2 \% \mathrm{CaCO}_{3}, 100 \mathrm{ml}$; and distilled water, $800 \mathrm{ml}$ ) under submerged conditions (23). A plug of mycelium on agar ( $7 \mathrm{~mm}$ diameter), from the actively growing margin of a 4-day-old culture of each isolate, was transferred to a tissue culture flask $(275 \mathrm{ml}$; Corning Inc., New York) containing $25 \mathrm{ml}$ of cleared V8$\mathrm{CaCO}_{3}$ liquid medium. The flasks were incubated vertically at $25^{\circ} \mathrm{C}$ in darkness for $24 \mathrm{~h}$. Each flask then was shaken (30 short strokes) to fragment hyphae that had grown out from the inoculum plug. Flasks were then incubated horizontally under the same conditions. After 6 days, $100 \mathrm{ml}$ of SDW was added to each flask, and the mycelial mat sank to the bottom of the liquid within few seconds. The flasks were further incubated vertically at $18^{\circ} \mathrm{C}$ in darkness for 10 weeks. Four samples of submerged mycelium were removed from each flask for each isolate and examined for chlamydospore formation by light microscopy. Twenty arbitrarily selected chlamydospores were measured for diameter and wall-thickness for each isolate. In colonies in which chlamydospores were not observed, the entire colony was checked with a dissecting microscope $(\times 60)$. The experiment was repeated once. Two replications were included in each experiment. Each flask was considered a replication.
Random amplified polymorphic DNA (RAPD) analysis. Twenty-four isolates of $P$. capsici from six different locations (four isolates per location) (Table 1) were assessed for genetic differences by RAPD analysis. A total of 25 decanucleotide primers (Operon Tech., Alameda, CA) were screened using DNA extracted from four test isolates of $P$. capsici, selected from among the 24 isolates, which represented different levels of virulence. Seven of the primers (OPA-03, OPA-04, OPA-10, OPA-11, OPB-13, OPC-09, and OPD-04) were selected for this study based on the number of clear, reproducible bands amplified from the test isolates and the production of polymorphic bands that distinguished the test isolates. The sequences of the primers were OPA-03: AGTCAGCCAC; OPA-04: AATCGGGCTG; OPA10: GTGATCGCAG; OPA-11: CAATCGCCGT; OPB-13: TTCCCCCGTC; OPC09: CTCACCGTCC; and OPD-04: TCTGGTGAGG. DNA amplification was performed in a thermal cycler (PTC-200; MJ Research Inc., Waltham, MA) with one cycle at $94^{\circ} \mathrm{C}$ for $5 \mathrm{~min}, 36^{\circ} \mathrm{C}$ for $2 \mathrm{~min}$, and $70^{\circ} \mathrm{C}$ for $2 \mathrm{~min}$, followed by 44 cycles at $94^{\circ} \mathrm{C}$ for $1 \mathrm{~min}, 36^{\circ} \mathrm{C}$ for $1 \mathrm{~min}$, and $70^{\circ} \mathrm{C}$ for $2 \mathrm{~min}$, and a final cycle at $70^{\circ} \mathrm{C}$ for $10 \mathrm{~min}$. Each RAPD reaction was done in a total volume of $25 \mu \mathrm{l}$, containing $30 \mathrm{ng}$ of genomic DNA, $1 \times$ PCR buffer, $120 \mu \mathrm{M}$ of each dNTP, $0.4 \mu \mathrm{M}$ of primer, and 2.5 units of $\mathrm{Taq}$ polymerase (KlenTaq; Ab Peptides Inc., St. Louis, MO). Amplified products were separated by electrophoresis in 2\% agarose gels (Low EEO; Fisher Scientific, Fair Lawn, NJ) at a constant $70 \mathrm{~V}$ in $1 \times$ TAE buffer for $4 \mathrm{~h}$ at room temperature. Fragments were visualized under UV light after staining with ethidium bromide and photographed. RAPD reproducibility was confirmed by repeating the reactions at least twice for each isolate.

A binary data matrix was prepared for each isolate and primer in which a RAPD band was scored as 1 when present or 0 when absent. A matrix of genetic distance coefficients for each pair of isolates was calculated using the Nei and $\mathrm{Li}(16)$ equation: $\mathrm{GD}_{(i j)}=1-\left[\left(2 N_{(i j)} /\left(N_{(i)}+N_{(j)}\right)\right]\right.$, where $N_{(i j)}$ is the total number of bands common to isolates $i$ and $j$, and $N_{(i)}$ and $N_{(j)}$ are the total numbers of bands present in $i$ and $j$ isolates, respectively. A dendrogram was constructed from the distance matrix by the unweighted pair group method algorithm (UPGMA) cluster analysis using PAUP 3.1 program (developed by D. L. Swofford, Laboratory of Molecular Systematics, Smithsonian Institution, Washington, DC.). Statistical significance of the dendrogram branches was assessed through bootstrap with 1,000 replications.

Virulence test. Twenty-four isolates of $P$. capsici, used in the RAPD analysis (Table 1), were tested for their virulence on pumpkin seedlings in a greenhouse. Sporangial suspensions were prepared from 6-day-old cultures of $P$. capsici grown on LBA at $24^{\circ} \mathrm{C}$ under continuous white fluorescent light. Ten milliliters of SDW was added to each plate, and the plate was gently shaken to suspend sporangia in water. The suspension was incubated at $20^{\circ} \mathrm{C}$ for $1 \mathrm{~h}$ to allow the sporangia to release their zoospores. Zoospores were separated from the empty sporangia by passing the suspension through a twolayered facial tissue. The concentration of zoospores was adjusted to $2 \times 10^{5}$ zoospores per ml of SDW using a hemacytometer.

Seeds of processing pumpkin (cv. Dickinson) were sown in seed flats with 12 holes $(6 \times 7 \times 5 \mathrm{~cm}$ each, one seed per hole) containing steamed greenhouse soil mix (soil:peat:perlite; $2: 1: 1$ ) and grown in a greenhouse at 23 to $25^{\circ} \mathrm{C}$. Four-week-old seedlings were inoculated by adding $5 \mathrm{ml}$ of the zoospore suspension $\left(2 \times 10^{5}\right.$ spores per $\mathrm{ml}$ of SDW) onto soil surface around the seedling in each hole. Seedlings were watered $1 \mathrm{~h}$ prior to inoculation to keep the soil wet. After inoculation, the seedlings were watered again. Seedlings were kept on the greenhouse bench in a completely randomized design with three replications. A seed flat containing 12 seedlings was considered to be one replicate.

Beginning the day after inoculation, seedlings were watered twice daily. The incidence and severity of disease was evaluated daily for 15 successive days beginning the day after inoculation. Disease severity was evaluated on a scale of 0 to 3 , where $0=$ no symptoms, $1=$ stem lesion without wilting, $2=$ wilting and girdled stem without damping-off of seedlings, and 3 = girdled stem with dampingoff of seedlings. The experiment was repeated twice. The data were analyzed using the analysis of variance procedure of SAS, and treatment means were compared using Fisher's protected LSD test $(P=$ 0.05).

\section{RESULTS}

Sporangial morphology. All isolates produced papillate and deciduous sporangia on long pedicels that were mostly ellipsoid to ovoid. The mean length of sporangia among the isolates ranged from 42.2 to $55.4 \mu \mathrm{m}$, and mean breadth of sporangia varied from 24.0 to $39.1 \mu \mathrm{m}$. The length/breadth ratio of sporangia ranged from 1.3 to 1.8 among the isolates. Mean pedicel length ranged from 34.3 to 101.4 $\mu \mathrm{m}$.

PCR-based identification of isolates. All of the isolates tested with the $P$. capsici specific primer PCAP, in combination with ITS primer ITS1, yielded the expected 172-bp product. Thus, identification of the isolates as $P$. capsici was confirmed.

Colony characteristics. Isolates of $P$. capsici tested had four different growth patterns: cottony, petaloid, rosaceous, and stellate, with the occurrence of $5,28,14$, 
and $53 \%$, respectively (Table 1). Isolates from the same field had similar growth patterns. All of the isolates grew at temperatures of $10,15,20,24,30,32,35$, and $36^{\circ} \mathrm{C}$, with the exception of isolates $\mathrm{Pc} 1$, Pc2-1, Pc2-5, and ATCC-15427, having cottony growth pattern, which did not grow at $36^{\circ} \mathrm{C}$. Only isolates Pc24-1, Pc242, Pc24-3, Pc24-4, Pc24-5, Pc24-6, Pc31, Pc35-6, Pc35-9, Pc35-10, and Pc38-11 grew at $38^{\circ} \mathrm{C}$ (approximately $0.4 \mathrm{~mm} /$ day). Optimum temperature for growth among the isolates varied from 24 to $32^{\circ} \mathrm{C}$.

Mating type. All 57 isolates of $P$. capsici tested were heterothallic. Thirty-one isolates were A1 mating type and 26 were A2 mating type (Table 1 ). Of seven fields from which multiple isolates were obtained, only A1, only A2, and both A1 and A2 mating types were found in 3,2, and 2 fields, respectively. All of the oospores examined had amphigynous antheridia. The mean diameter of the oospores ranged from 22.1 to $38.4 \mu \mathrm{m}$. The mean oospore diameter in A1 mating type isolates (33.92 $\mu \mathrm{m})$ was significantly $(P=0.05)$ greater than in A2 mating type $(25.55 \mu \mathrm{m})$.

Chlamydospore formation. Among the 24 isolates tested, nine (Pc1, Pc2-1, Pc10, Pc24-2, Pc24-4, Pc33-1, Pc35-4, Pc36-7, and Pc38-12) produced chlamydospores in both of the replicated experiments. Chlamydospores were single, terminal, or intercalary, and pale yellow. The diameter of chlamydospores ranged from 20.0 to $27.5 \mu \mathrm{m}$. Wall thickness of chlamydospores ranged from 2.0 to $2.5 \mu \mathrm{m}$.

RAPD analysis. Seven primers used in the RAPD analysis generated simple banding patterns that revealed DNA polymorphism among the isolates. A total of 65 polymorphic bands were scored in repeated amplifications from the 24 isolates of $P$. capsici (Fig. 1). None of the primers distinguished all the isolates as different genotypes. Cluster analysis separated the isolates into six RAPD groups (Fig. 2). RAPD groups corresponded to pathogenicity traits, not to location of origin. The genetic distance values ranged from 0.03 to 0.45 . The first group (A) included four isolates (Pc1, Pc2-1, Pc34-7, and Pc34-8) from two towns (Pekin, Machinaw). The second group (B) included eight isolates (Pc38-12, Pc38-13, Pc33-1, Pc33-9, Pc335, Pc13, Pc35-10, and Pc35-4) from four towns (Manito, Green Valley, Allentown, Pekin). The first and second groups were separated at a genetic distance of 0.33 . The third group (C) included three isolates (Pc33-3, Pc34-3, and Pc34-11) from two towns (Green Valley, Machinaw) and was
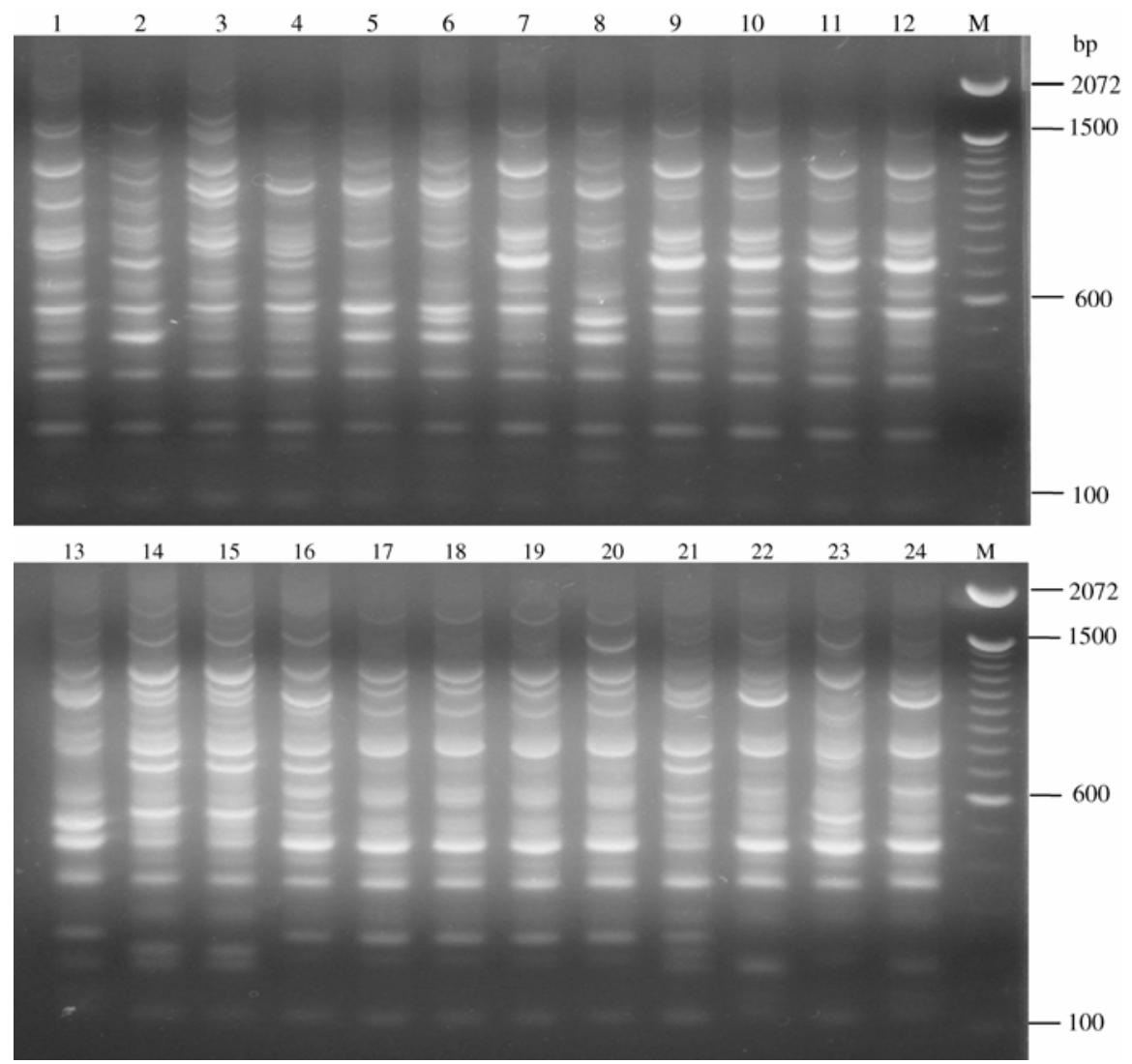

Fig. 1. Random amplified polymorphic DNA (RAPD) profiles generated by primer OPA-11 for 24 isolates of Phytophthora capsici from 10 processing pumpkin fields at six locations in central Illinois. Marker (M) is 100-bp DNA ladder. Amplified DNA from isolates ("M" suffix is omitted) in the lanes from left to right are Pc1, Pc2-1, Pc10, Pc13, Pc24-2, Pc24-4, Pc38-12, Pc38-13, Pc33-1, Pc33-3, Pc33-5, Pc33-9, Pc34-3, Pc34-7, Pc34-8, Pc-34-11, Pc35-4, Pc35-6, Pc35-7, Pc35-10, Pc36-5, Pc36-7, Pc36-8, and Pc36-9. separated from groups $\mathrm{A}$ and $\mathrm{B}$ with a distance of 0.36. Isolate Pc36-5 (Forest City) did not cluster with any isolate and constituted a group alone (D) and was separated from groups $\mathrm{A}, \mathrm{B}$, and $\mathrm{C}$ with a distance of 0.37 . The fifth group (E) included three isolates (Pc35-6, Pc35-7, and Pc24-2) from two towns (Allentown, Manito) and was separated from other groups with a distance of 0.40 . The last group (F) included five isolates (Pc36-7, Pc36-9, Pc36-8, Pc24-4, and Pc10) from three towns (Forest City, Manito, Pekin) and was separated with a distance of 0.45 from the other five groups. Five of the groups contained isolates of both mating types.

Virulence of isolates. There was a significant $(P=0.05)$ variation in disease incidence and severity among the isolates irrespective of location. The lowest disease incidence of $8.3 \%$ was scored for isolates Pc33-3 and Pc34-3, while the highest of 100\% was scored for Pc35-4 and Pc35-10 (Fig. 3). The lowest mean disease severity of 0.01 was scored for isolates Pc34-3, while the highest of 2.52 was scored for isolate Pc35-6 (Fig. 4). Overall, isolates from the Machinaw location were less virulent. The mean disease severity values of 2.52, 2.45, and 2.42 for the isolates Pc35-6, Pc35-7, and Pc24-2, respectively, were significantly higher than those of the rest of the isolates. Based on disease severity values, the isolates were separated into six groups: I (Pc1, Pc2-1, Pc34-7, and Pc34-8); II (Pc38-12, Pc33-1, Pc33-9, Pc33-5, Pc13, Pc38-13, Pc35-10, and Pc35-4); III (Pc33-3, Pc34-3, and Pc3411); IV (Pc36-5); V (Pc35-6, Pc35-7, and Pc24-2); and VI (Pc36-7, Pc36-9, Pc36-8, Pc24-4, and Pc10), which correspond to RAPD groups A, B, C, D, E, and F, respectively (Fig. 2).

\section{DISCUSSION}

The results of this study showed significant differences in virulence among $P$. capsici isolates from processing pumpkin in Illinois, which agrees with reports by Ristaino (19) and Lee et al. (13) that there are significant differences in aggressiveness among $P$. capsici isolates from cucurbits and peppers.

Cluster analysis separated 24 isolates of P. capsici into six RAPD groups, which corresponded to six pathogenicity groups (Fig. 2). Lamour and Hausbeck (12) reported genetic variation among isolates of $P$. capsici from different locations in Michigan. Abu-El Samen et al. (1) also reported genetic variation among isolates of $P$. infestans from different locations. Relationships between RAPD groups and virulence of isolates of Aphanomyces euteiches, another oomycete pathogen, irrespective of geographical origin, have been reported (14). In our study, there was no significant relationship between either virulence or genetics of the isolates and 
locations (towns). The probable reason for the difference between our findings and those reports by other investigators is that all six towns in our studies are located within an approximately $30-\mathrm{km}$ radius; thus, the locations are not separated from each other by long distances.

In the present study, both A1 and A2 mating types of $P$. capsici were identified in two of seven processing pumpkin fields. All of the isolates produced oospores when compatible isolates of $\mathrm{A} 1$ and $\mathrm{A} 2$ mating types were paired in culture. Similar results in squash and pepper fields have been reported by Ristaino (19). The presence of both mating types together in processing pumpkin fields increases the potential of oospore production and genetic recombination of $P$. capsici.

In our study, $37.5 \%$ of the isolates of $P$. capsici tested produced chlamydospores irrespective of mating type. It has been reported that isolates of $P$. capsici from black pepper, macadamia, and cocoa produced chlamydospores $(2,24,25)$. However, there is no report of chlamydospore formation by isolates of $P$. capsici from cucurbits. Thus, this is the first report of chlamydospore formation by $P$. capsici from pumpkin. Chlamydospores may overwinter in the fields and serve as a primary source of inoculum.

It has been reported that diameter of oospores of $P$. capsici varies with pairing of different A1 or A2 mating types $(19,22)$. Mchau and Coffey (15) reported that oospore size varied considerably even within a single pair. The usefulness of oospore dimensions for separating different morphological forms or species of Phytophthora has been evaluated $(7,9,15)$. In this study, all of the isolates identified as the A1 mating type produced larger oospores when pairing with A2 isolate ATCC-15399 than with isolates of the A2 mating type that produced oospores pairing with A1 isolate ATCC-15427. According to the existing knowledge, oospore size could not be used to accurately determine mating types or virulence of $P$. capsici isolates from processing pumpkin. Some

\section{Genetic distance}

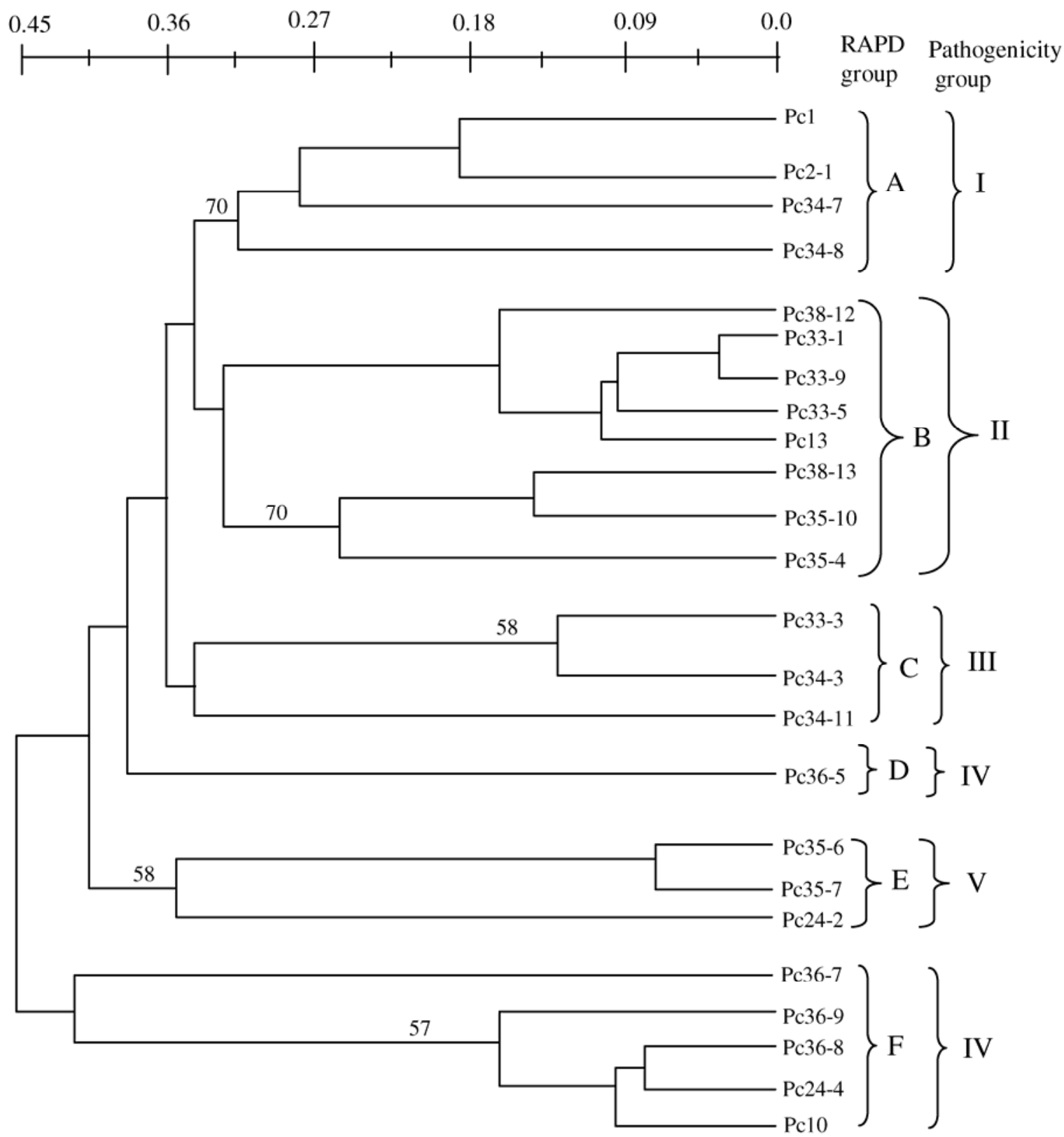

Fig. 2. Clustering of 24 isolates of Phytophthora capsici from 10 different processing pumpkin fields at six locations in central Illinois using PAUP program. Genetic distance was calculated according to the equation developed by Nei and Li (16). Bootstrap (1,000 replicates) values greater than $50 \%$ are shown on branches. Pathogenicity groups are based on disease severity. 
heterothallic isolates of A1 (Pc1, Pc2-1, and Pc9) and A2 (Pc2-5, Pc4, and Pc12) mating types produced few homothallic oospores in solo cultures on LBA medium in this study. Similar findings have been reported for isolates of $P$. capsici from pepper, cucumber, squash, cocoa, and other heterothallic species of Phytophthora $(10,19)$.

$P$. capsici has been characterized by its ability to grow at temperatures higher than $35^{\circ} \mathrm{C}(18)$. In our study, three isolates ( $\mathrm{Pc} 1$, Pc2-1, and Pc2-5) that have a cottony growth pattern and an isolate from ATCC
(ATCC-15427) with the same growth pattern did not grow at $36^{\circ} \mathrm{C}$. This indicates that $P$. capsici isolates having cottony growth pattern are more sensitive to temperatures higher than $35^{\circ} \mathrm{C}$ compared with the isolates with stellate, petaloid, or rosaceous growth patterns. Inability of a $P$.

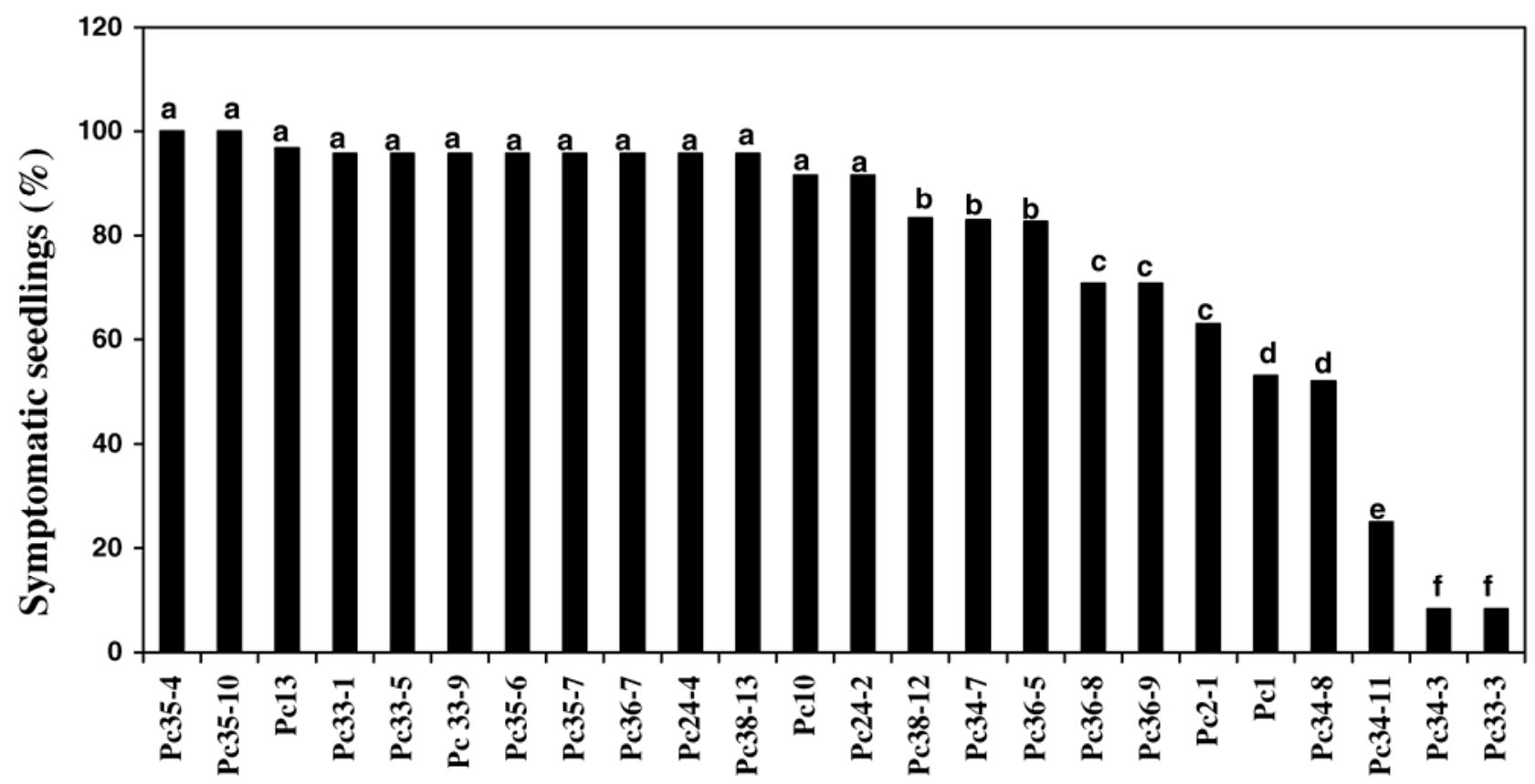

Isolate

Fig. 3. Percent symptomatic processing pumpkin seedlings inoculated with Phytophthora capsici isolates from processing pumpkins. Percent symptomatic seedlings were determined 2 weeks after inoculation. Bars labeled with the same letter are not significantly different $(P=0.05)$ according to Fisher's protected LSD test.

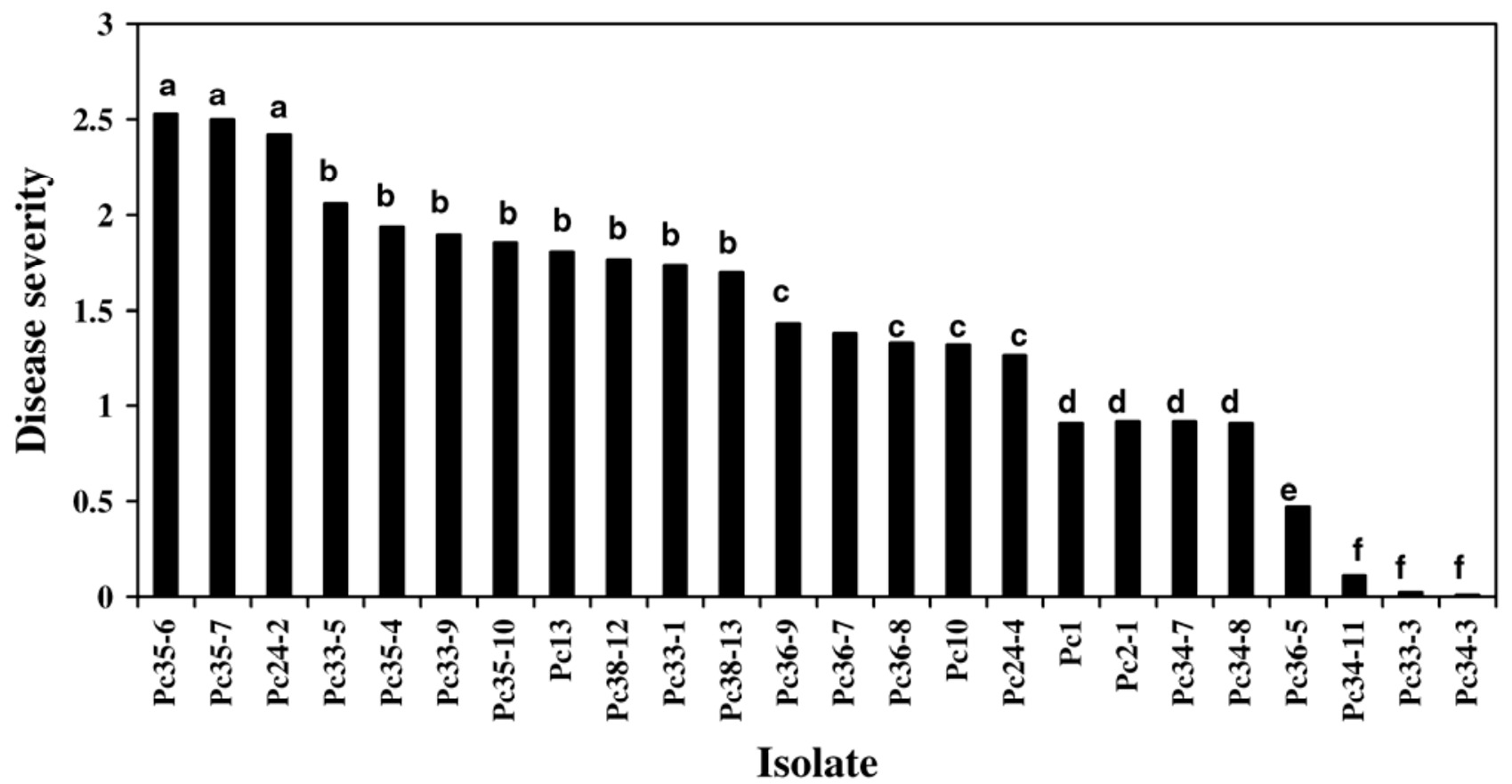

Fig. 4. Mean disease severity on processing pumpkin seedlings inoculated with Phytophthora capsici isolates from processing pumpkins. Disease severity was determined 2 weeks after inoculation using a scale of 0 to 3 , where $0=$ no symptoms, $1=$ stem lesion without wilting, $2=$ wilting and girdled stem without damping-off of seedlings, and $3=$ girdled stem with damping-off of seedlings. Bars labeled with the same letter are not significantly different $(P=$ 0.05) according to Fisher's protected LSD test. 
capsici isolate from ATCC and a pepper isolate of $P$. capsici to grow at $36^{\circ} \mathrm{C}$ had been reported previously (19). Therefore, growth at temperatures greater than $35^{\circ} \mathrm{C}$ cannot be a definitive character for identification of $P$. capsici. These findings agree with those of other researchers $(15,19)$ who have questioned the reliability of this characteristic for identification of Phytophthora species.

The results of this study showed that virulence of $P$. capsici isolates from different processing pumpkin fields varied significantly. The variability in virulence of $P$. capsici may explain some of the difficulties that hinder development of cucurbit cultivars resistant to Phytophthora blight, or developing other effective control measures against $P$. capsici. The results from this study and findings by other investigators $(12,13)$ show that in developing effective strategies for management of $P$. capsici, a large pool of isolates from different locations must be tested. Development of sensitive DNA-based diagnostic methods for determining virulence of $P$. capsici isolates will be useful.

\section{ACKNOWLEDGMENTS}

This research was supported in part by funds from NCR-IPM Grants (CSREES Project No. 2002-34103-11745), NCR-SARE Grants (Project No. LNCO3-228), and Nestle Food, Inc. We are grateful to S. Bekal from the Department of Crop Sciences, University of Illinois, for her assistance in conducting RAPD tests.

\section{LITERATURE CITED}

1. Abu-El Samen, A. E., Secor, G. A., and Gudmestad, N. C. 2002. Analysis of genetic variability among asexual progeny of $P$. infestans using virulence, RAPD and AFLP markers. (Abstr.) Phytopathology 92:S137.

2. Alizadeh, A., and Tsao, P. H. 1985. Chlamydospore formation in Phytophthora palmivora MF4. Trans. Br. Mycol. Soc. 85:71-79.

3. Babadoost, M. 2000. Outbreak of Phy- tophthora foliar blight and fruit rot in processing pumpkin fields in Illinois. Plant Dis. $84: 1345$.

4. Babadoost, M., and Islam, S. Z. 2003. Fungicide seed treatment effects on seedling damping-off of pumpkin caused by Phytophthora capsici. Plant Dis. 87:63-68.

5. Bowers, J. H., Papavizas, G. C., and Johnston, S. A. 1990. Effect of soil temperature and soilwater metric potential on the survival of Phytophthora capsici in natural soil. Plant Dis. 74:771-777.

6. Duniway, J. M. 1983. Role of physical factors in the development of Phytophthora diseases. Pages 175-187 in: Phytophthora: Its Biology, Taxonomy, Ecology, and Pathology. D. C. Erwin, S. Bartnicki-Garcia, and P. H. Tsao, eds. American Phytopathological Society, St. Paul, $\mathrm{MN}$.

7. Erwin, D. C. 1983. Variability within and among species of Phytophthora. Pages 149165 in: Phytophthora: Its Biology, Taxonomy, Ecology, and Pathology. D. C. Erwin, S. Bartnicki-Garcia, and P. H. Tsao, eds. American Phytopathological Society, St. Paul, MN.

8. Hwang, B. K., and Kim, C. H. 1995. Phytophthora blight of pepper and its control in Korea. Plant Dis. 79:221-227.

9. Kaosiri, T., Zentmyer, G. A., and Erwin, D. C. 1980. Oospore morphology and germination in the Phytophthora palmivora complex from cocoa. Mycologia 72:888-907.

10. Kellam, M. K., and Zentmyer, G. A. 1986. Comparisons of single oospore isolates of Phytophthora species from naturally infected cocoa pods in Brazil. Mycologia 78:351-358.

11. Kreutzer, W. A., Bodine, E. W., and Durrel, L. W. 1940. Cucurbit diseases and rot of tomato fruit caused by Phytophthora capsici. Phytopathology 30:972-976.

12. Lamour, K. H., and Hausbeck, M. K. 2001. Investigating the spatiotemporal genetic structure of Phytophthora capsici in Michigan. Phytopathology 91:973-980.

13. Lee, B. K., Kim, B. S., Chang, S. W., and Hwang, B. K. 2001. Aggressiveness to pumpkin cultivars of isolates of Phytophthora capsici from pumpkin and pepper. Plant Dis. 85:497-500.

14. Malvick, D. K., and Percich, J. A. 1998. Genotypic and pathogenic diversity among peainfecting strains of Aphanomyces euteiches from the central and western United States. Phytopathology 88:915-921.

15. Mchau, G. R. A., and Coffey, M. D. 1995 Evidence for the existence of two subpopulations in Phytophthora capsici and a redescription of species. Mycol. Res. 99:89-102.

16. Nei, M., and Li, W. H. 1979. Mathematical model for studying genetic variation in terms of restriction endonucleases. Proc. Natl. Acad. Sci. USA 76:5269-5273.

17. Nelson, A. J., Elias, K. S., Arevalo G., E., Darlington, L. C., and Bailey, B. A. 1997. Genetic characterization by RAPD analysis of isolates of Fusarium oxysporum f. sp. erythroxyli associated with an emerging epidemic in Peru. Phytopathology 87:1220-1225.

18. Newhook, F. J., Waterhouse, G. M., and Stamps, D. J. 1978. Tabular key to the species of Phytophthora de Bary. Mycol. Pap. 143 Commonwealth Mycological Institute, Kew, Surrey, England.

19. Ristaino, J. B. 1990. Intraspecific variation among isolates of Phytophthora capsici from pepper and cucurbit fields in North Carolina. Phytopathology 80:1253-1259.

20. Ristaino, J. B., Larkin, R. P., and Campbell, C. L. 1994. Spatial dynamics of disease symptom expression during Phytophthora epidemics in bell pepper. Phytopathology 84:1015-1024.

21. Ristaino, J. B., Madritch, M., Trout, C. L., and Parra, G. 1998. PCR amplification of ribosomal DNA for species identification in the plant pathogen Genus Phytophthora. Appl. Environ. Microbiol. 64:948-954.

22. Savage, E. J., Clayton, C. W., Hunter, J. H., Brenneman, J. A., Laviola, C., and Gallegly, M. E. 1968. Homothallism, heterothallism, and interspecific hybridization in the genus Phytophthora. Phytopathology 58:1004-1021.

23. Tsao, P. H. 1971. Chlamydospore formation in sporangium-free liquid cultures of Phy tophthora parasitica. Phytopathology 61:14121413

24. Tsao, P. H. 1991. The identities, nomenclature and taxonomy of Phytophthora isolates from black pepper. Pages 185-211 in: Diseases of Black Pepper. Proc. Int. Pepper Comm. Workshop Black Pepper Dis., Goa, India. Y. R. Sarma and T. Premkumor, eds.

25. Uchida, J. Y., and Aragaki, M. 1985. Occurrence of chlamydospores in Phytophthora capsici. Mycologia 77:832-835. 